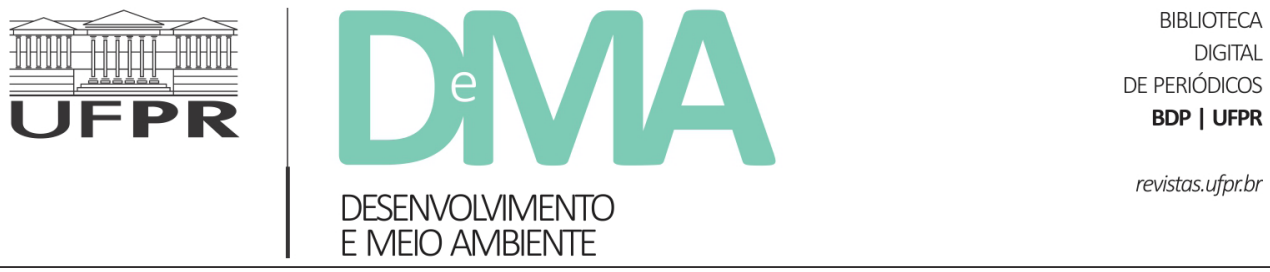

\title{
Como Belo Monte se tornou sustentável? Ponderações baseadas no estudo da controvérsia da pesca na região de Altamira/PA
}

\section{How did Belo Monte become sustainable? Weightings based on the study of the fisheries controversy in the Altamira/PA region}

\author{
Camila PRATES $^{1 *}$, Jalcione ALMEIDA ${ }^{2}$ \\ RS, Brasil. \\ ${ }^{2}$ Universidade Federal do Rio Grande do Sul (UFRGS), Porto Alegre, RS, Brasil. \\ *E-mail de contato: camilapratescs@gmail.com
}

${ }^{1}$ Grupo de Pesquisa Tecnologia, Meio Ambiente e Sociedade (TEMAS), Universidade Federal do Rio Grande do Sul (UFRGS), Porto Alegre,

Artigo recebido em 26 de junho de 2020, versão final aceita em 29 de março de 2021, publicado em 4 de novembro de 2021.

RESUMO: Este artigo mapeia e discute a controvérsia na pesca gerada pelas perturbações no rio Xingu em decorrência da construção da Usina Hidrelétrica Belo Monte. As alterações na pesca local, longe de serem consensuais, foram captadas por meio do mapeamento da controvérsia sobre a pesca na região, da observação e realização de entrevistas. Recorre-se à categoria de controvérsia tecnocientífica para mostrar como as alegações no âmbito tecnocientífico são formuladas, disputadas e encerradas não com base em um consenso científico, mas com auxílio de uma rede de sustentação construída por humanos (pescadores, indígenas, pesquisadores) e não humanos (peixes, relatórios, financiamento, acordos) que exerce mais influência sobre os demais. A pesquisa apontou que a suspensão da controvérsia em questão agrava os conflitos ambientais, uma vez que existem diferentes versões ambientais sobre o rio Xingu, apreendidas pela ciência, mas que são ignoradas no âmbito da legitimação dos impactos da obra. $\mathrm{O}$ estudo conclui que a controvérsia é encerrada à força com a demarcação política "Belo Monte é sustentável", que age com a ajuda de diretrizes científicas favorecendo estudos em larga escala sobre o rio, apoiadas pela rede do programa de ação que constrói a Usina.

Palavras-chave: controvérsias tecnocientíficas; Usina Hidrelétrica Belo Monte; conflitos ambientais; estudos ambientais.

ABSTRACT: This article maps and discusses the controversy in the fishing generated by the disturbances in the Xingu 
River due to the construction of the Belo Monte Hydroelectric Plant. The changes in local fisheries, far from being consensual, were captured through mapping the fisheries controversy in the region, observing and conducting interviews. The category of techno-scientific controversy is used to show how the claims in the techno-scientific realm are formulated, disputed and closed not based on scientific consensus, but with the help of a support network built by humans (fishermen, indigenous people, researchers) and non-humans (fish, reports, financing, agreements) that has more influence over the others. The research pointed out that the suspension of the controversy in question aggravates environmental conflicts, since there are different environmental versions about the Xingu River, apprehended by science, but which are ignored within the scope of legitimization of the impacts of the work. The study concludes that the controversy is forcibly ended with the political demarcation "Belo Monte is sustainable", which acts with the help of scientific guidelines favoring large-scale studies of the river, supported by the network of the action program that builds the Plant.

Keywords: technoscientific controversies; Hydroelectric Plant Belo Monte; environmental conflicts; environmental studies.

\section{Introdução}

A propalada sustentabilidade da Usina Hidrelétrica Belo Monte está longe de ser consensual. Para melhor ponderar sobre aspectos que constituem essa afirmação, ela será explorada através de versões científicas sobre as alterações na pesca local. Esse mapeamento visa responder ao seguinte questionamento: Belo Monte é sustentável para quem e para qual finalidade? Ao final, este artigo fornece pistas para responder a essa questão, pautando-se no estudo da controvérsia tecnocientífica envolvendo o empreendimento no que tange às questões pesqueiras na região.

As alterações da pesca na região são expostas pelos cientistas de forma dissonante: de um lado, há o entendimento de que a barragem não gera impactos na pesca, fortalecendo, portanto, o rótulo da sustentabilidade e, de outro, entende-se que a barragem gera danos irreversíveis à natureza e na vida dos pescadores da região, demonstrando que a delimitação dos impactos pelo empreendedor não absorve os danos que a obra gera. Neste artigo, mobiliza-se a terminologia dos impactos ambientais, acionada por órgãos licenciadores e consultorias contratadas, entendendo que ela mobiliza a falsa ideia de que área receptora dos projetos tem a capacidade de absorver os impactos, quando em realidade resta a gestão da distribuição ou atenuação dos seus danos colaterais (Magalhães \& Hernandez, 2009). Mobiliza-se, portanto, a acepção de impactos em sua forma crítica para demonstrar que existem parâmetros pré-estabelecidos no acionamento do termo, que atuam no jogo de buscar "menores impactos" ou as "maiores mitigações e compensações", que, como será visto, são insuficientes no contexto dos danos ambientais gerados na região. Por meio da proposta metodológica latouriana, este artigo demonstra que os estudos tecnocientíficos são fortes aliados na produção de dados sobre os impactos da obra e, consequentemente, implicam no discurso da sustentabilidade de Belo Monte.

Nos últimos 100 anos, o país recorreu ao uso da energia hidrelétrica por meio do aproveitamento do potencial hidráulico de seus rios. Para essa tarefa, faz-se necessária a existência de um desnível no solo capaz de proporcionar a captação da energia que, por sua vez, é produzida por meio da vazão de água existente entre os desníveis - estes podem ser naturais, pela existência de cachoeiras, ou podem ser 
produzidos artificialmente, por meio da construção de barragens para represamento dos rios.

Para a construção artificial dos desníveis é necessário levantar, a partir da tecnociência disponível, um barramento (ou mais de um, dependendo do projeto). Para que sua construção seja efetivada, uma hidrelétrica deve se adequar à regulamentação da Política Nacional do Meio Ambiente (PNMA), que faz a mediação entre as instituições estatais e os construtores das usinas. A construção de uma hidrelétrica é um processo no qual a tecnociência e as decisões políticas e econômicas estão imbricadas nas transformações ambientais com base na utilização de conceitos, métodos e técnicas acionados pelas ciências.

A Usina Hidrelétrica Belo Monte foi considerada um dos projetos da linha de frente do Programa de Aceleração do Crescimento (PAC). Este, segundo o Ministério do Planejamento, tem o objetivo de executar grandes obras de infraestrutura e de logística, incluindo obras energéticas buscando acelerar o desenvolvimento com sustentabilidade, associado a investimentos em programas sociais, como o "Minha Casa Minha Vida" e "Luz para Todos" (PAC, 2018). Autores como Müller \& Ab'saber (1998) consideram hidrelétricas ecológica e economicamente viáveis por três motivos: i) por serem consideradas produtoras de energia limpa ${ }^{1}$ proveniente de matriz renovável ${ }^{2}$; ii) porque sua construção é feita para operar por muitos anos; e iii) porque o custo de produção é mais competitivo entre as demais fontes de energia como a biomassa, carvão mineral, nuclear, eólica, gás natural, óleo combustível e óleo diesel. Em contrapartida, a construção de barragens é criticada acadêmica e socialmente por gerar danos ambientais irreparáveis, visto que alteram a natureza e a dinâmica social associada nas regiões onde se instalam e pelo custo de sua produção ser subdimensionado às custas das externalidades ambientais deixadas ao gerenciamento e convívio das populações locais (Magalhães \& Hernandez, 2009).

No contexto da construção de Belo Monte, a ciência ganha centralidade na delimitação da viabilidade ambiental e dos impactos da obra. Entram no embate dois tipos de estudos: i) aqueles construídos por empresas de consultoria ${ }^{3}$, chamados aqui de estudos oficiais; e ii) os elaborados por pesquisadores que relatam as alterações na região, chamados de estudos extraoficiais. O primeiro grupo realiza seus estudos vinculados ao empreendedor, uma vez que a consultoria ambiental é para "uma atividade especializada de prestação de serviços caracterizada pelo uso intensivo de conhecimento" (Costanzo \& Sánchez, 2013, s/p). Logo, a ciência produzida para fundamentar os estudos ambientais, como o Estudo de Impacto Ambiental (EIA) e o Plano Básico Ambiental (PBA), contém um objetivo $a$ priori: cumprir os requisitos técnicos e procedimentais do licenciamento ambiental para liberar a construção e o funcionamento do empreendimento.

\footnotetext{
${ }^{1}$ Sobre a controvérsia da energia limpa no Brasil e em Belo Monte ver estudo de Prates \& Peixoto (2020).

${ }^{2}$ As fontes renováveis representam $81,7 \%$ da oferta interna de eletricidade no Brasil, com destaque para a geração hidráulica que responde por $68,1 \%$ da oferta interna (EPE, 2018).

${ }^{3}$ Essas consultorias são contratadas pelo empreendedor com o fim de preencher os requisitos dos instrumentos de licenciamento e avaliação de impacto ambiental da PNMA. Esses requisitos estão vinculados à atuação do órgão ambiental que analisa os estudos de impacto para deliberar sobre a viabilidade ambiental das obras.
} 
Já no segundo grupo estão os estudos que analisam criticamente a construção da viabilidade ambiental da Usina, demonstrando as transformações ecológica e socioeconômicas na região, sendo realizados por pesquisadores vinculados a grupos de pesquisa ligados a universidades de distintas regiões do país, mas que se dedicam à Amazônia e aos estudos socioambientais. Estes realizam estudos geralmente descolados dos objetivos do empreendedor, conectando-se a entidades comprometidas com causas ambientais. No contexto de Belo Monte, esses dois grandes grupos disputam o diagnóstico da realidade gerada pelas alterações na região com a construção da Usina e a sustentabilidade a ela associada.

A abordagem sociológica sobre os efeitos da tecnologia e da ciência na vida social ganham projeção com a abordagem de Ulrich Beck (2010), que relaciona a tecnociência às modificações ambientais operadas pela ciência moderna. Esta ciência é dotada de um caráter dual, gerando riscos e promovendo a atenuação dos efeitos danosos por ela fomentados. Por seu caráter reflexivo, a ciência seria capaz de promover um tipo de "catástrofe emancipatória", sugerindo que após um desastre (como o evento nuclear de Fukushima, por exemplo) há um processo reflexivo capaz de evitar eventos semelhantes (Kinsella, 2015). Contudo, a ciência, ainda que seja suscetível a processos reflexivos, opera frequentemente exercendo o domínio da razão sobre a natureza. Segundo o autor, a impossibilidade de dominar a natureza é o motivo pelo qual não há como apontar os responsáveis pelos desastres, e conclui: "vivemos em um sistema de irresponsabilidade organizada" (Beck, 2011, s/p) no qual encontram-se várias causas para os efeitos gerados, sendo difícil desenvolver uma punição aos culpados. Segundo o autor, isso ocorre porque ao invés de responsabilizar os tomadores de decisões políticas e tecnocientíficas, influenciadas por políticos e empresários, joga-se a causa do evento em um desastre natural, que em tese não poderia ser totalmente previsto. Beck (2011) conclui que Fukushima aconteceu pelo arranjo que envolve decisões governamentais e econômicas equivocadas somadas à ausência de pressão da sociedade civil mobilizada, impossibilitando qualquer tipo de transparência ou controle social sobre os processos decisórios empresariais e políticos, resultando na construção de uma usina atômica em área onde terremotos são comuns, gerando risco de poluição nuclear de alcance global.

É interessante notar que a ciência é central na delimitação dos estudos ambientais e dos riscos - e na construção da percepção destes -, visto que muitos riscos escapam ao conhecimento da população por serem imperceptíveis, invisíveis (Beck, 2010). Essa centralidade é compartilhada pelas abordagens sociológicas no escopo dos Estudos Sociais em Ciência e Tecnologia (ESCT). Estes também corroboram com o autor no entendimento de que a ciência possui um caráter contraditório, mas se empenha em entendê-la refazendo o caminho percorrido para chegar a um determinado resultado científico, mapeando suas engrenagens e também as relações sociais que as constitui. Na situação de controvérsia sobre determinado fato científico é possível estender a discussão para fora dos muros da ciência, a fim de notar quais fatores sociais (contexto de produção, financiamento, entre outros), além dos internos, próprios ao método científico, promovem direcionamentos em seus resultados. Esse posicionamento transborda o limite construído artificialmente entre o fazer científico (e sua suposta neutralidade) e os direcionamentos políticos e empresariais. $\mathrm{Na}$ 
abordagem acadêmica dos ESCT há o entendimento compartilhado de que a ciência é também produzida socialmente e de que as tensões, direcionamentos políticos e econômicos são elementos importantes na sua constituição. Ou seja, possibilitam perceber os processos de captura acadêmica no alinhamento de interesses entre analistas, consultores, pesquisadores dos empreendedores e das populações locais.

O caráter contraditório da ciência foi explorado por Nunes e Matias (2003) na análise sobre a incineração de resíduos industriais perigosos em Portugal, inter-relacionando os temas relativos à ciência, técnicas, ambiente, conflitos e espaços democráticos. A ciência foi acionada para gerar informações sobre os efeitos da incineração dos resíduos industriais tóxicos na natureza e nas pessoas. Entretanto, a comissão científica, formada pelo governo português, apenas ratificou a segurança da incineração do material, excluindo da sua análise métodos alternativos e a formulação para uma estratégia integrada de gestão de resíduos industriais (Nunes \& Matias, 2003). Para além da avaliação tecnológica do incinerador para a queima de resíduos tencionava-se também quais atores seriam legítimos para participar do debate. O conflito político em torno do domínio do ambiente "têm vindo a reconfigurar o campo da luta política e da ação coletiva em torno de problemas ambientais" (Nunes \& Matias, 2003, p. 149), ampliando a ação política fora do ambiente burocrático, pré-determinado do estado português.

Em diálogo com a linha argumentativa exposta, Bruno Latour apresenta uma possibilidade teórica que considera a relação entre sociedade(s)- -natureza(s) na construção da ciência, não baseada no cosmos único, mononaturalista (Latour, 2018), tal como é explorada tradicionalmente pelas ciências sociais. Em sua abordagem, os enunciados científicos são etnografados. Esse exercício, segundo o autor, possibilita entender a produção interna da ciência e também os fatores sociais e grupos nela imbricados. A teoria sugere que enunciados científicos se tornam estáveis quando ultrapassam os questionamentos de posições contraditórias.

Neste artigo, destacamos o enunciado "a construção de Belo Monte não gera efeitos significativos na pesca da região", assegurado pelos actantes ${ }^{4}$ que fazem parte da rede do programa de ação de construção de Belo Monte, que será descrito ao longo do texto. A reflexão se dá através da abordagem latouriana, porque além do mapeamento dos argumentos técnicos e científicos, ela expõe como diferentes ontologias são construídas na relação dos pescadores com os peixes, com o rio Xingu e demonstra a emergência de coletivos políticos que buscam novas possibilidades de existir naquele ambiente.

Além desta introdução, este trabalho está estruturado em outras quatro seções: na primeira expõe-se o referencial teórico e a metodologia utilizada na pesquisa; na segunda, é apresentada a Usina e a rede que sustenta Belo Monte sob o signo da sustentabilidade; após, será descrita a controvérsia sobre os efeitos da pesca na região de Altamira. $\mathrm{Na}$ conclusão, algumas pistas são formuladas com o auxílio do referencial latouriano para responder à problemática proposta.

\footnotetext{
${ }^{4}$ Actante é o termo que Latour (2016) utiliza para descrever tanto atores humanos quanto não humanos que promovem a diferença (promovam significados) no curso de um acontecimento.
} 


\section{A controvérsia no entendimento latouriano}

Inspirado na bifurcação da natureza em Alfred Whitehead, Latour é animado a teorizar sobre a reinterpretação científica da experiência humana, partindo do pressuposto de que a realidade não é dividida em reinos da natureza e da cultura. Seguir os rastros da controvérsia sobre a pesca, à luz desse pressuposto, provoca a reflexão sobre o rio e os peixes enquanto estruturantes da vida dos pescadores. Aos actantes é oferecida a simetria generalizada, ou seja, o peso de suas agências opera simetricamente na construção ontológica ocorrida nas associações por eles estabelecidas em rede (Latour, 1994; 2000). Os actantes mapeados são aqueles que realizam uma modificação no curso da ação e, quando relacionados, denotam as atividades ontológicas construídas na rede (Queiroze Melo, 2008).

Em linhas gerais, Latour $(1994 ; 2016)$ considera que os momentos de controvérsias são elucidativos porque revelam uma série de actantes, ligações, negociações sociais e políticas que se unem para estabilizar determinado conhecimento tecnocientífico como, por exemplo, "Belo Monte não gera efeitos significativos na pesca local", transformando-os em fatos. Como efeito do mapeamento aqui proposto, verifica-se a atuação de grupos que objetivam manter suas construções de sociedade e natureza, reforçando repertórios e também modos de vida específicos, e, ao fazê-lo, excluem outras formas de viver naquele local.

Segundo Latour (1994; 2016), o encerramento de controvérsias é o momento em que a ciência estabiliza os fatos e os confinam em monolíticas caixas-pretas. Entretanto, esse encerramento deixa rastros que nos levam ao momento que a ciência está em construção, e que os fatos estão enredados em múltiplas mediações carregadas de incertezas. Assim, pode-se rastrear a construção dos fatos para retraçar os arranjos complexos que envolvem o consenso científico, as estratégias de interessamentos utilizadas, os actantes humanos e não humanos (rio Xingu, relatórios, artigos científicos, entre outros) distribuídos em redes sociotécnicas. As estratégias de interessamentos se dão no sentido de um incentivo direcionado, ou seja, de exercer poder sobre algo ou alguém (Latour, 2016). Nesse sentido, as redes são produzidas por meio dos actantes que conseguem traduzir determinado evento, sendo essa tradução amparada por outros actantes. As traduções ${ }^{5}$ são impressões dos actantes (versões compartilhadas) sobre determinado fenômeno. Nesse movimento, os actantes se encarregam de arregimentar outros em suas ligações compondo sua rede de sustentação.

A metodologia utilizada se ampara no mapeamento da controvérsia sobre a pesca e na posterior descrição dos actantes em programa de ação, formado pelos actantes que trabalham para transformar o enunciado em um fato, e em antiprograma de ação formado por aqueles que trabalham para transformar o enunciado em uma ficção (Latour, 2016). As reflexões aqui propostas são consequentes da pesquisa de campo realizada entre os meses de abril e maio de 2014, em Altamira e na Volta Grande do Xingu (PA). Nesse período, estavam sendo construídas as estruturas físicas que compõem a Usina (diques de

${ }^{5}$ Tradução significa “ao mesmo tempo transcrever, transpor, deslocar, transferir e, portanto, transportar transformando" (Latour, 2016, p. 30). 
contenção, Sítio Pimental, Sítio Belo Monte, canal de derivação). Os dados foram coletados e analisados tendo como inspiração o método da cartografia das controvérsias (Latour, 2016) associada à Teoria Ator-Rede (TAR), cujo objetivo é descrever as variações entre fato e ficção de um enunciado. As informações coletadas na análise de conteúdo realizada nos estudos denominados oficiais e independentes foram complementadas com as entrevistas e também por meio dos relatos dos pescadores. Além das pesquisadoras envolvidas nos dois estudos que se contrapõem, foram entrevistados pescadores da colônia de pesca de Altamira e pescadores indígenas da aldeia Muratu, por serem diretamente afetados. As entrevistas semi-estruturadas foram direcionadas aos efeitos da obra na pesca da região e ocorreram em abril e maio de 2014.

Para seguir o enunciado "Belo Monte não gera efeitos significativos na pesca local" foi preciso acessar artigos científicos sobre a controvérsia, entrevistar actantes que dela participavam direta $\mathrm{e}$ indiretamente, e descrever eventos lá vivenciados. A rede dos estudos independentes foi acessada para expor os impactos na pesca na Volta Grande do rio Xingu, por meio do trabalho de Francesco \& Carneiro (2015), de entrevistas com técnicos do Instituto Brasileiro do Meio Ambiente e dos Recursos Naturais Renováveis (IBAMA), com procuradores do estado do Pará, indígenas Juruna (Yudjá) da Terra Indígena Paquiçamba e com pescadores na região de Altamira. Para acessar os estudos oficiais recorreu-se ao "Estudo de Impacto Ambiental" (Leme, 2009) e também foi realizada entrevista com a pesquisadora coordenadora do Programa "Pesca Sustentável" (Eletrobrás, 2009), que levanta dados sobre a pesca para a Norte Energia.

Como recurso didático, os estudos que compõem a controvérsia foram categorizados em dois grupos $^{6}:$ i) os estudos independentes, realizados por pesquisadores de diversas áreas articulados por associações civis, apoio de universidades e dos pescadores e indígenas da região; e ii) os estudos oficiais, realizados por empresas de consultoria e pelos pesquisadores por elas contratados para cumprir as normativas legais, como a construção de relatórios, de estudos e projetos para atender aos padrões exigidos pelo órgão ambiental competente.

\section{Do grande reservatório à tecnologia fio d'água: a construção de Belo Monte sustentável}

Desenvolvimento sustentável é uma ideia-conceito que acompanha e interage com as diferentes fases da construção de Belo Monte. Esta começa a ser lapidada ao final dos anos de 1980 e é expresso no Relatório Brundtland como "aquele que atende às necessidades do presente sem comprometer a possibilidade de as gerações futuras atenderem as suas próprias necessidades" (Comissão Mundial sobre Meio Ambiente e Desenvolvimento, 1991, p. 46). Esse relatório é considerado o início da institucionalização do termo e do ambientalismo liberal em nível global (Sklair, 2019). O desenvolvimento sustentável prega um crescimento mais equitativo com o uso dos recursos tecnológicos para diminuir

\footnotetext{
${ }^{6}$ Esses grupos foram assim organizados como resultado da pesquisa de campo, enquanto a pesquisa de campo, a observação participante e a análise documental estavam em andamento. Ou seja, não são categorias dadas a priori, mas sim resultado do posicionamento dos atores, por intermédio de mediadores distintos. É um retrato produzido após a aplicação da metodologia explicitada.
} 
os impactos ambientais nos "recursos naturais". Em tese, o conceito imbrica o desenvolvimento econômico, o manejo responsável do ambiente e a tecnociência. As mudanças promovidas pela ideia-conceito se dão no âmbito das legislações ambientais e de sua institucionalização nas esferas do Estado. Assim, conectada à noção de sustentabilidade está a ideia de que devem ser adotadas mudanças institucionais de adoção de princípios racionais e científicos no embasamento das decisões econômicas e políticas. Nesse contexto, a ciência está intimamente ligada à definição dos desafios ambientais (Irwin, 2008) associados à sustentabilidade. Entretanto, o desenvolvimento sustentável tem sido frequentemente capturado pelo desenvolvimento econômico e tem servido retoricamente tanto a partidos de esquerda como de direita para fomentar o desenvolvimento econômico que mais convém (Bibeau, 2011).

Como é um termo que admite múltiplas interpretações, utilizá-lo sem que haja consenso entre os interlocutores é supor que tanto o desenvolvimento quanto a sustentabilidade são a mesma coisa (ou têm o mesmo significado) para os atores imbricados. $\mathrm{O}$ que ocorre, na maioria das vezes, é que o uso inquestionável do termo movimenta consigo um modelo etnocentrista de sociedade (industrial-capitalista), de ambiente (o natural apartado do social) e de tecnologia (moderna), que opera "desconsiderando a história material situada dos agentes que habitam os diversos territórios" (Blanco-Wellls, 2019, p. 178 - tradução livre) de modo que é impossível implementar as mudanças associadas ao termo sem ameaçar as atuais condições de existência.

A Usina Belo Monte é a maior hidrelétrica construída inteiramente em solo nacional. Sua his- tória se prolonga há 30 anos e o projeto inicial foi redesenhado três vezes. Na década de 1970, auge da ditadura militar no país, Belo Monte havia sido projetada como um complexo de cinco hidrelétricas. Sevá Filho (2005) relata que após alguns rearranjos, em 1988, os estudos de inventário no rio Xingu foram reformulados e aprovados pelo Departamento Nacional de Águas e Energia Elétrica (DNAEE), através da Portaria $n^{\circ} 432$ de agosto de 1988. Também nessa época o Ministério de Minas e Energia (MME), por meio da Portaria $n^{\circ} 1077$, autorizou a Eletronorte a realizar os estudos de viabilidade do complexo de duas hidrelétricas no Xingu (Babaquara-Kararaô), formando um grande reservatório que inundaria grande área de terra, incluindo terras indígenas (Sevá Filho, 2005).

Em 1989, já no período de reabertura democrática, os povos indígenas explicitaram sua reação contra a decisão do governo de construir a mega usina no Encontro dos Povos Indígenas do Xingu, realizado em Altamira, organizado por lideranças indígenas auxiliadas por entidades da sociedade civil (Cimi, 2008). O evento tornou-se um marco importante na oposição ao projeto, atingindo a atenção da mídia internacional.

Em 1990, as questões ambiental e indígena passam a delimitar a terceira alteração do projeto. Desta vez, a Usina seria construída para aproveitar o desnível de 90 metros com a construção de canais (na época, dois canais eram projetados) que desviariam o rio e evitariam que as terras indígenas fossem alagadas (Falcão, 2010). Esse arranjo não inundaria a Volta Grande do Xingu, mas a manteria sob o regime de vazão reduzida e dependente de um hidrograma de consenso ${ }^{7}$ regulado pela barragem

Hidrograma de consenso é um acordo realizado pela Agência Nacional das Águas (ANA), Agência Nacional de Energia Elétrica (ANEEL) e 
principal de Belo Monte, para controlar o fluxo de água do rio destinado à Volta Grande do Xingu.

Assim, com base nesta proposta, Belo Monte foi reformulada pelo setor elétrico e as alterações aceitas pelo Congresso Nacional em julho de 2005, durante o governo Lula, através do Decreto Legislativo $n^{0} 788 / 2005$. Nesse contexto, o projeto Belo Monte foi retomado como único empreendimento a ser construído no rio Xingu. A Usina ocupa o potencial hidráulico do rio Xingu, está localizada no estado do Pará e tem seus dois barramentos edificados nos municípios de Altamira e Vitória do Xingu. Na Figura 1 é possível ver o arranjo de duas barragens já construídas: o barramento principal, conhecido por sítio Pimental e a barragem secundária que comporta a casa de força principal, o sítio Belo Monte. Nesse arranjo, a Volta Grande do Xingu (em azul claro), que acolhe uma sociobiodiversidade completa formada por espécies de peixes endêmicas e terras indígenas, fica dependente do fluxo do rio que é liberado pela barragem principal.

A decisão de construir uma usina a fio d'água ${ }^{8}$ gerou controvérsias. De um lado, alguns consultores do setor elétrico da época alegavam que o

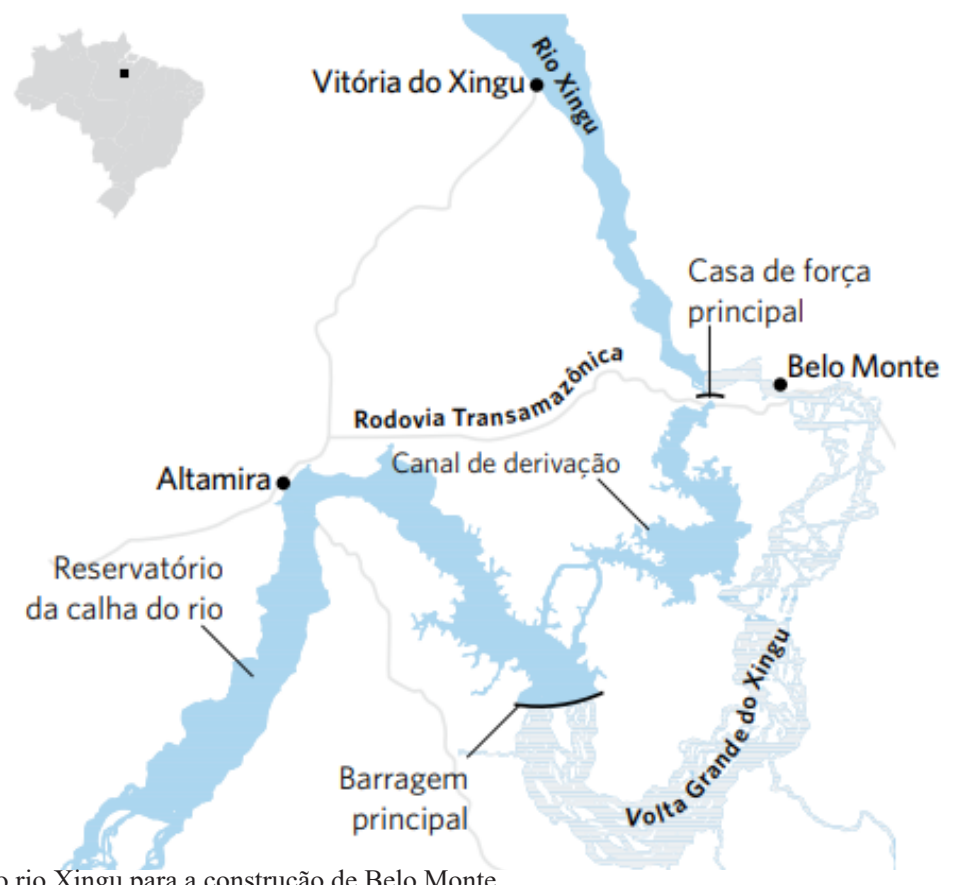

FIGURA 1 - Desvio do rio Xingu para a construção de Belo Monte.

FONTE: FGV (2016, p.13).

IBAMA, no qual pesquisadores, técnicos e a empresa delimitaram a quantidade de água do rio que será disponibilizada pela barragem principal para manter a biodiversidade da Volta Grande do Xingu.

${ }^{8}$ Usinas fio d'água são hidrelétricas construídas próximas à superfície do rio e "utilizam turbinas que aproveitam a velocidade do rio para gerar 
governo não deveria ter cedido à pressão social para tornar Belo Monte um barramento de tipo fio d'água em nome da sustentabilidade (Tancredi \& Abbud, 2013), isso porque argumentavam que, com o passar do tempo, essa decisão geraria "prejuízos ambientais nas emissões de carbono decorrentes da geração térmica" (Tancredi \& Abbud, 2013, p. 18). A lógica dos consultores se amparava no argumento que a energia que Belo Monte não geraria teria de ser reposta pela matriz térmica ${ }^{9}$. De outro lado, o arranjo feito pela tecnologia, baseada na união do "tripé" desenvolvimento econômico, ambiental e social, amplifica os efeitos nocivos da obra, uma vez que constrói uma ideia de sustentabilidade ao diminuir a área alagada.

A lógica dos consultores e do governo da época pode ser interpretada pela "lógica das alternativas infernais" (Stengers \& Pignarre, 2005), uma vez que sustenta a construção de Belo Monte para suprir uma necessidade de gerar energia sustentável, renovável e limpa frente aos impactos gerados pelas termelétricas (Leroy \& Acselrad, 2011). Contudo, ao aderir a uma definição de tecnologias denominadas "limpas" ou "sustentáveis", com visão restrita de uma "economia verde", tende a promover e acentuar conflitos pela distribuição desigual dos danos ambientais gerados pela economia, podendo fomentar, consequentemente, injustiças ambientais (Porto et al., 2013).
No contexto deste estudo, os conflitos ambientais se acirraram quando decidem construir um aproveitamento hidrelétrico por geração a fio d'água porque essa reformulação tecnocientífica acrescenta artificialmente o rótulo da sustentabilidade pelos empreendedores - sendo também o posicionamento oficial do Estado brasileiro em relação à Usina uma vez que, para atender aos impeditivos legais, o novo projeto isentaria as terras indígenas do alagamento proposto nos projetos anteriores.

Por meio da controvérsia da pesca percebe-se que a manobra técnica utilizada para sustentar a construção de Belo Monte gerou insustentabilidades nos meios de vida na região, por revelar que não apenas o ambiente, como comumente se traduz os conflitos ambientais (Zhouri \& Laschefski, 2010; Prates \& Peixoto, 2020), a gramática através da qual se traduz o rio Xingu é fruto de descompassos mais amplos, que envolvem formas de compreensão dos ambientes (Fleury \& Almeida, 2013; Fleury et al., 2014). Esses ambientes lutaram para serem reconhecidos e foram disputados, conforme será visto na descrição a seguir da controvérsia.

Antes de rastrear a controvérsia aqui em destaque, é necessário explorar sociologicamente como os grupos de cientistas envolvidos nas controvérsias disputam a construção de fatos, assim como apresentar efeitos gerados pelo encerramento da controvérsia na diversidade de formas de ser e de viver naquele lugar.

energia (...) reduzem as áreas de alagamento e não formam reservatórios para estocar a água" (ANEEL, 2008, p. 50). Pela ausência de reservatório, essas usinas diminuem tanto a capacidade de armazenamento de água, quanto de geração energética (ANEEL, 2008).

9 De acordo com Faria (2004), a matriz energética brasileira gera energia firme (que corresponde à energia média gerada pelo sistema nacional interligado quando ele está no período crítico, ou seja, nos períodos de secas nos quais a geração hídrica é menor) na combinação da produção hídrica e térmica. A energia térmica, por sua vez, é gerada pela produção de calor através das fontes: gás natural, carvão mineral, biomassa, nuclear (EPE, 2016). 
4. A controvérsia sobre a pesca: exposição de interesses distintos em torno do rio Xingu

Nesta seção, será exposta a controvérsia sobre a alteração na dinâmica da pesca na região enquanto efeito da construção da Usina do Sítio Pimental. Essa controvérsia se dá entre os pesquisadores que embasam os estudos oficiais, contratados pelo empreendedor, a Norte Energia SA (NESA), e os estudos independentes, realizados por pesquisadores vinculados a universidades brasileiras e instituições preocupadas com a questão socioambiental, como o Instituto Socioambiental (ISA).

Os dois estudos que se contradizem são o Pesca Sustentável (Eletrobrás, 2009), financiado pela Norte Energia, e o "contraestudo" "Atlas dos impactos da UHE Belo Monte sobre a pesca" (Francesco \& Carneiro, 2015), organizado pelas pesquisadoras Cristiane Carneiro, da UFPA, e Ana de Francesco, da Universidade Estadual de Campinas, e apoiado pelo ISA. Esses estudos revelam dados contraditórios sobre os pontos de pesca e a quantidade de peixes disponíveis no entorno do Sítio Pimental, disputando versões para o enunciado gerido pela rede do programa de ação, "a construção de Belo Monte não gera efeitos significativos na pesca da região". Também foram entrevistados quatro pescadores na colônia de pesca de Altamira e pescadores indígenas da Aldeia Muratu.

A rede do programa de ação foi mapeada através dos interlocutores do programa Pesca Sustentável (Eletrobrás, 2009), contratado pela Norte Energia para monitorar áreas extensas de pesca, compreendendo o baixo e o médio Xingu (Figura 2), ou seja, para monitorar regiões consideradas áreas de influência da barragem, concluindo que não há alterações significativas na atividade de pesca na região. Metodologicamente, este estudo dividiu a macrorregião em setores menores: setor I (Iriri), setor II (Reservatório), setor III (Volta Grande), setor IV (Baixo Xingu), setor V (Barramento Pimental e Belo Monte) e setor VI (Bacajá), trecho que corresponde ao baixo e ao médio Xingu.

As escolhas teórico-metodológicas do Pesca sustentável possibilitaram verificar as dinâmicas dos

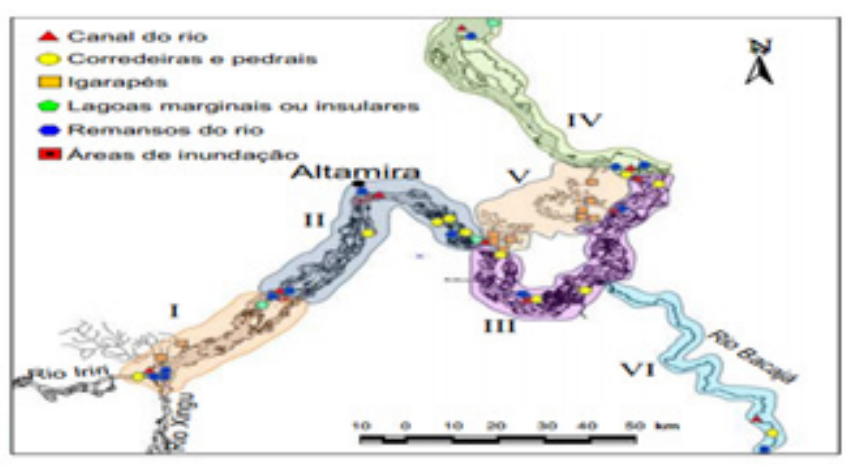

FIGURA 2 - Pontos de análise do programa Pesca Sustentável. FONTE: Eletrobrás (2009). 
peixes em áreas de mais de mil quilômetros de rio. Essa metodologia é justificada pelo comportamento dos peixes que ultrapassam os limites geográficos artificiais impostos pelos seres humanos (Entrevista com coordenadora do Programa Pesca Sustentável, Belém, maio de 2014). Os dados da rede do Programa são computados desde 2010, em toda a área citada anteriormente e não apenas na área de abrangência direta do empreendimento, que varia entre 200 e $300 \mathrm{~km}$ de área de interesse, ou seja, na área que os pescadores mais sentem as alterações na pesca. Segundo a pesquisadora do Programa, possuir dados temporais e espaciais é importante para acompanhar a dinâmica da pesca a fim de comparar ao longo do tempo o que acontece na região:

neste momento nós estamos observando que em 2013 teve uma caída de esforço, ou seja, a produção diminuiu porque houve menos gente pescando em relação a outras áreas. Isso foi relatado. Só que nós trabalhamos com um indicador que se chama CPUE. A CPUE é a quantidade capturada dividida pelo total de pescadores, ou barcos ou horas pescando, que a gente chama isso de esforço de pesca. Então na pesca tu tens um indice desse jeito. Tu divides o total que eles capturam pelo número de pescadores ou pelas horas que eles pescaram, tem várias unidades e tu consegues um indicador que nós chamamos indicador de produtividade. É esse indicador que a gente compara; então não éo total de captura, mas éo total de captura dividido. Quando tu vês, por exemplo, o esforço total de 2013 foi menor que o de 2012. Ai eles dizem que não estão indo pescar porque não tem peixe. Só que quando tu calculas o que eles pescaram no tempo que eles pescaram, a CPUE dá igual, idêntica, ou seja, eu não consigo ver. Então é isso que começou com toda a briga dos pescadores, que eles dizem que eu estou falsificando os dados (Trecho de entrevista com a coordenadora do Programa Pesca Sustentável, Belém, maio de 2014).
Após apresentar resultados preliminares constatando que não haveria grande impacto na pesca da região, conforme relatado acima, houve perda de confiabilidade dos pescadores na pesquisa sendo que muitos pararam de responder aos questionários aplicados. O foco da controvérsia é a área de abrangência do Projeto Pesca Sustentável (Eletrobrás, 2009), que é ampla e não dá conta de investigar os impactos sobre a pesca de forma pontual (nas áreas de interesse dos pescadores), como relatou a pesquisadora responsável pelo Programa em entrevista.

Mas caso os pontos de análise dos estudos oficiais fossem realizados nas áreas fragilizadas (conforme a visão dos pescadores), seus resultados preliminares seriam diferentes? Para responder a essa questão, a pesquisadora reforçou a necessidade de fazer verificações mais específicas e, para tanto, seria preciso aumentar o orçamento do Projeto para financiar pesquisadores, materiais, entre outros insumos: agora, o que a gente está propondo? É fazer um estudo focado na região. É isso que a gente está propondo, mas não estava planejado, então é dinheiro a mais (Trecho de entrevista com a coordenadora do Programa Pesca Sustentável, Belém, maio de 2014). Esse diagnóstico mais específico não foi completado devido ao congelamento do orçamento destinado aos projetos do PBA, por que os valores destinados para esses estudos "mitigatórios" estavam diretamente vinculados ao valor total da obra, que aumentou significativamente nos últimos sete anos, passando de 19 bilhões de reais (valor de leilão em 2010) para o valor especulado de 30 bilhões de reais e ainda sem estimativa real do custo final.

A rede do antiprograma de ação indica o contrário. Ela foi mapeada através do contraestudo construído que objetivou "dar voz a esses pesca- 
dores, colocando em um mapa seu conhecimento tradicional sobre o território, as relações ali implicadas e as alterações decorrentes da instalação da usina sobre as áreas de pesca da região" (Francesco \& Carneiro, 2015, p. 5). Esse estudo, grosso modo, objetivava criticar e transformar o enunciado a construção de Belo Monte não gera efeitos significativos na pesca da região em ficção. O contraestudo coloca-se como tradutor dos argumentos dos pescadores e defende que, com o início da construção do Sítio Pimental, a rotina de pesca foi alterada na região. Boias amarelas foram colocadas ao longo do rio Xingu, nas proximidades do Pimental, para proibir o fluxo de embarcações nas áreas que antes eram locais de pesca, mas que agora sofrem com efeitos diretos da obra (Francesco \& Carneiro, 2015):

[d]epois da barragem ninguém vê o peixe, o peixe sumiu. Eles dizem que isso [a construção do sítio Pimental] não impacta o peixe. Aquela zuada de gente fechando o rio, aquelas maquinadas todas dentro d'água, aquela zuada, aqueles problemas, viu?... Os peixes vão tudo saindo fora. Estourando bomba, estourando aquelas pedras. O peixe vai embora. ( $\mathrm{Sr}$. V., entrevista em Altamira, abril/2014).

As alterações foram retratadas pelos próprios pescadores que não conseguem pescar a mesma quantidade que pescavam antes da construção da usina. Em visita realizada na colônia de pesca em Altamira, no ano de 2014, entrevistei um grupo de pescadores que relataram alterações em suas rotinas devido aos impactos da obra. O primeiro problema levantado por eles foi o seguinte: em terra indígena, pescador não pode pescar. Um dos entrevistados estava com os equipamentos de pesca (malhadeira, barco, isopor, entre outros) em posse dos indígenas que o surpreenderam pescando em suas terras. Com a perda das áreas de pesca, as opções viáveis ficam escassas, aumentando a pressão sobre as terras indígenas, pois são próximas a Altamira. O segundo problema relatado foi a necessidade de procurar por outras áreas de pesca, mais distantes de Altamira, o que acarretava em maior prejuízo com o aumento do tempo no rio e, consequentemente, maior gasto de combustível e comida em uma mesma pesca que, outrora, era realizada próxima de casa: nós pegávamos até $200 \mathrm{~kg}$ de peixe em seis dias de pesca, gerando um lucro de $R \$ 200,00$ por dia em tempos bons (pescador V. entrevista em Altamira, abril de 2014).

Detalhando, o novo local de pesca do pescador V. e de tantos outros pescadores da região passou a ser no rio Iriri, a seis dias de deslocamento. Os pescadores de Altamira estimam que, além de aumentar o custo da pesca, os peixes não são mais vendidos em Altamira, mas nas localidades próximas à atual região de pesca. Em Altamira, os peixes vêm, em sua maioria, de outras localidades, inclusive do rio Amazonas: nessa mesma rua que hoje é da Norte Energia, antes existia um monte de 'isopores', vendia-se uma grande quantidade de peixes, recorda o entrevistado. A venda de peixes na semana santa, em que o volume é tradicionalmente maior, foi motivo de preocupação para pescadores e moradores, dado o número reduzido de peixes disponíveis. Outra mudança sentida pelos pescadores é que os frigoríficos de gado estão ocupando espaço que antes eram de peixes: já tem dois frigorificos só nessa rua (pescador V. entrevista em Altamira, abril de 2014).

Os efeitos da construção da barragem também foram diretamente sentidos nas terras indígenas, visto que aumentou a pressão na pesca na Volta Grande do Xingu por pescadores não indígenas, gerando toda sorte de conflitos na busca por espaços 
de pesca na região. Além da pesca comercial e para subsistência, também foi afetada a pesca de peixes ornamentais de espécies endêmicas da região. Portanto, além da diminuição quantitativa há também a redução de espécies capturáveis, diminuindo tanto a biodiversidade quando as fontes de alimentação e de geração de renda aos pescadores da região.

Os estudos independentes pretendem dar visibilidade aos pescadores indígenas e não indígenas, aos ribeirinhos, aos pontos de pesca que foram perdidos, aos modos de vida que foram alterados pela disponibilidade de peixes na alimentação local, aos peixes ornamentais que complementavam a renda dos pescadores. Todos esses actantes são acionados para argumentar que a região no entorno do Sítio Pimental está sofrendo, desde 2011, com os efeitos da turbidez da água, que afasta os peixes dos locais onde são tradicionalmente pescados, e da poluição do rio devido às contínuas explosões realizadas na construção da obra, efeitos que foram amplificados com o fechamento do rio Xingu, em 2014.

Os estudos em disputa revelam que os efeitos negativos que a Norte Energia precisa mitigar na pesca são bastante distintos. De um lado, demonstrado pelos dados oficiais, não há efeitos na pesca da região, de outro lado, os efeitos negativos se acumulam e intensificam problemas cotidianos da região, como a disponibilidade de peixes, como a pesca como meio de vida, sendo, portanto, efeitos não mitigáveis pelas propostas da empresa, devido sua complexidade e extensão. Contudo, apenas quando a empresa reconhece que determinado problema existe, por meio de seus estudos oficiais, é que ele passa a ser considerado como um problema a ser resolvido. Assim, para que os pescadores e indígenas da região sejam considerados "atingidos" pela obra, a ciência mobilizada pela rede do pro- grama tem que atestar e, a partir disso, os impactos sobre a atividade da pesca podem ser mitigados com recursos oriundos do empreendedor (Francesco \& Carneiro, 2015).

Estudos independentes trazem a versão dos fatos com base na experiência dos pescadores sobre o evento. Estes relatam que sofrem pela falta de peixes (no sentido quantitativo, mas também na diversidade acessada), com as alterações de seus cotidianos. Esses pesquisadores, por sua vez, traduzem os problemas oriundos da obra para a linguagem científica e esses dados são utilizados "como consultoria científica" para o setor jurídico embasar as reivindicações judiciais (e acordos extrajudiciais) dos pescadores. Assim, os resultados desses estudos passam a ser constantemente citados como referência científica para embasar os argumentos das Ações Civis Públicas (Rodrigues, 2013).

Como reação ao estudo promovido pela rede do programa de ação, mobilizações foram realizadas pelos pescadores e indígenas da Volta Grande do Xingu. O ano de 2012 culminou com a realização de prensas no Sítio Pimental, termo utilizado por indígenas e pescadores para nomear as paralisações nos canteiros da Usina, a fim de reivindicar direitos frente aos efeitos negativos da obra. Essas paralisações geraram um acordo de canteiro - expressão utilizada pela procuradora de Altamira para descrever os acordos realizados entre os pescadores e a Norte Energia durante a ocupação do canteiro de obras -, a fim de buscar soluções para os problemas vinculados à alteração das áreas de pesca (ver Figura 3).

O supracitado acordo firmado entre o empreendedor, o Ministério de Pesca e Aquicultura e os pescadores parece, à primeira vista, um acordo favorável aos pescadores da região. Contudo, mui- 
tas ações desse acordo já estavam contempladas nas condicionantes ambientais, delimitadas pelo IBAMA para acompanhar os impactos de Belo Monte sobre a pesca, como, por exemplo, o monitoramento do Sistema de Transposição de Peixes (STP), que inclui a construção do "corredor de peixes", o monitoramento pesqueiro envolvendo o Programa Pesca Sustentável (Eletrobrás, 2009) e o laboratório de estudos do campus da UFPA. De acordo com o valor estimado acima (Figura 3), esses projetos somam mais de 12 milhões de reais do saldo total destinado ao atendimento das demandas dos pescadores. O restante dos recursos disponíveis no Acordo de Cooperação Técnica é destinado à construção de infraestrutura, como as sedes das colônias de pesca nos municípios impactados. Entretanto, estão ausentes no acordo as indenizações sobre as atividades econômicas perdidas e apoio à capacitação e cursos que promovam a inserção desses profissionais em outras atividades econômicas (Francesco \& Carneiro, 2015).

A rede do Programa é fortalecida pelos pesquisadores consultores que constroem o enunciado a construção de Belo Monte não gera efeitos significativos na pesca da região. Nesta rede, os relatórios técnicos fazem a mediação entre os re-

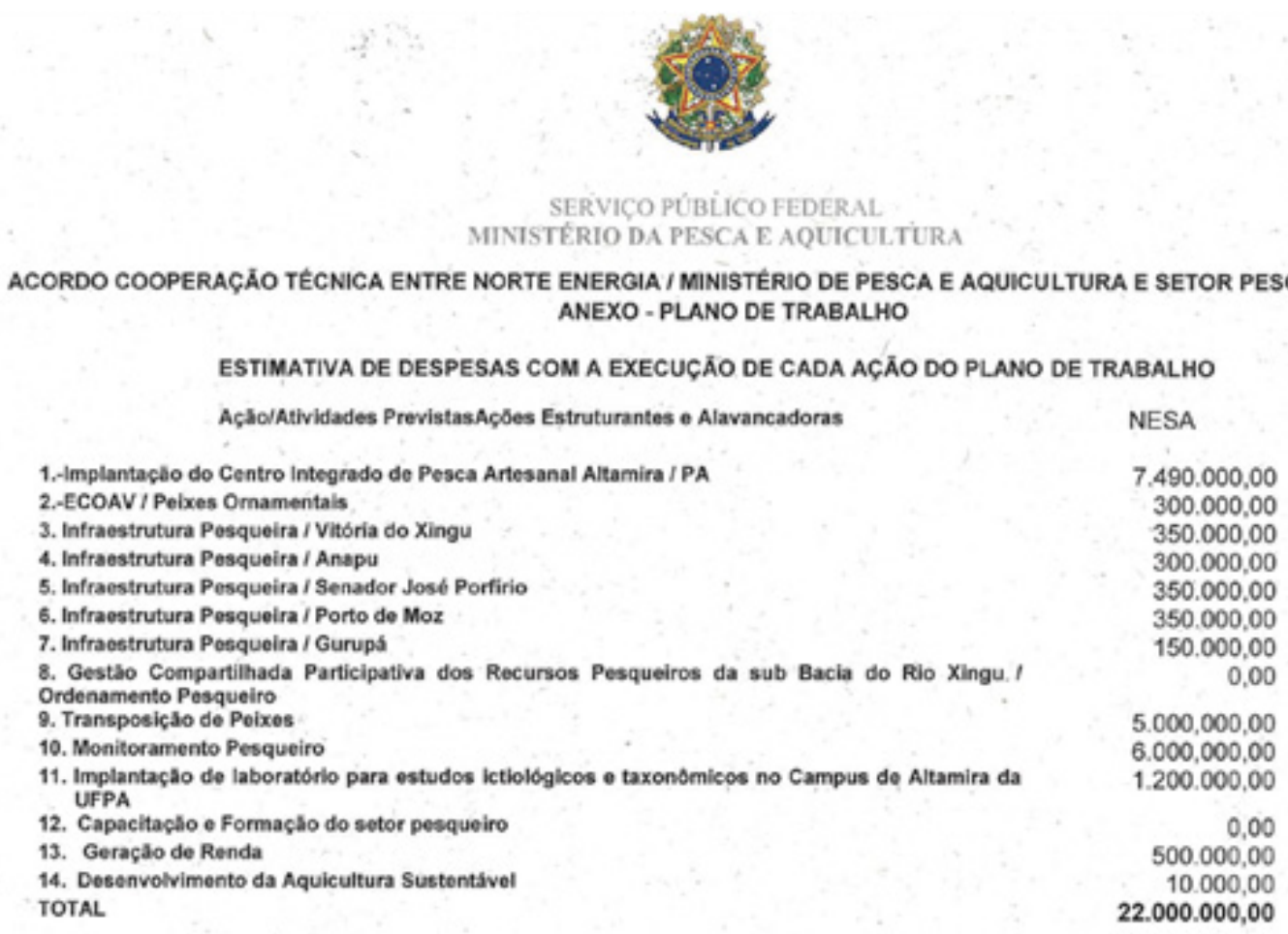

FIGURA 3 - Acordo de Cooperação Técnica.

FONTE: NESA (2014, p. 30). 
sultados dos estudos que traduzem a realidade dos pescadores e a continuidade do licenciamento de Belo Monte. Portanto, os relatórios são actantes essenciais na tradução dos pescadores, por meio deles a tradução sobre a atividade dos pescadores chega à análise para os trâmites processuais pelos técnicos do IBAMA.

A rede do antiprograma de ação, construída pelos estudos independentes, busca transformar o enunciado em ficção. Nessa rede, seus actantes se transformam em porta-vozes científicos dos problemas que os pescadores e indígenas da região vivenciam na pesca. A conexão dos estudos com o IBAMA se dá indiretamente por meio da atuação da defensoria pública e mais fortemente por meio da atuação do Ministério Público Federal, que utilizam dados desses estudos para fundamentar as ações civis mobilizadas.

Quais mecanismos, então, contribuem para encerrar a controvérsia? De um lado, o estudo oficial traduz o rio Xingu em grandes extensões, com grandes financiamentos para um trabalho de campo bastante longo; de outro, o rio Xingu é traduzido por estudos mais localizados que consideram o que dizem os pescadores indígenas e não indígenas sobre a alteração dos seus cotidianos no que tange à pesca na região, auxiliando na construção dos dados da pesquisa. A controvérsia sobre os efeitos da pesca revela que a ciência aciona elementos políticos, sociais e ambientais em suas escolhas metodológicas e direcionam os resultados dos estudos (em áreas extensas, efeitos locais não identificados versus estudos localizados, realizados com auxílio dos pescadores e indígenas da região).
As ligações existentes na rede do programa de ação evidenciam uma estrutura pré-determinada, que é composta pelos procedimentos do licenciamento ambiental. Essa estrutura limita a atuação de actantes reforçando a existência de poderes assimétricos ao compararmos com a atuação da rede do programa de ação e do antiprograma de ação. A assimetria de poder é refletida no encerramento forçado da controvérsia através do acordo de cooperação técnica, realizado por pressão dos pescadores, o que foi chamado de "acordo de canteiro", no qual evidencia que a obra continuava impactando a pesca na região. Este acordo, além de não dar conta das demandas mais estruturantes da vida dos pescadores, serviu para que a Norte Energia colocasse a controvérsia em suspenso, fortalecendo o enunciado "a construção de Belo Monte não gera efeitos significativos na pesca da região". Nesse contexto, as empresas de consultoria, relatórios técnicos, Norte Energia e IBAMA se mostram decisivos para compor a ação. Assim, fica claro que a composição, não só do curso da ação, mas da sociedade e da natureza da região, mais uma vez é delineada por actantes hegemônicos que produzem o cenário que torna a Usina ambientalmente sustentável. Há, portanto, uma assimetria no encerramento da controvérsia, uma vez que as versões oficiais são delineadas pelas redes nas quais órgãos estatais e privados (como a Norte Energia e as empresas de consultorias) estão envolvidas. Note-se que a controvérsia é encerrada por estratégias políticas, uma vez que, no plano científico os posicionamentos contrários à construção de Belo Monte não tiveram espaço para que seus dados fossem debatidos e acolhidos na discussão sobre os impactos da obra. 


\section{Para concluir: a produção do consenso sobre a sustentabilidade de Belo Monte- algumas pistas sobre o encerramento da controvérsia}

Ao mapear as versões científicas sobre as alterações na pesca retoma-se os questionamentos feitos inicialmente para afirmar: Belo Monte é sustentável apenas para a rede do programa de ação, que a constrói, e nesse processo foram substancialmente diminuídos os efeitos adversos da obra na atividade da pesca para contemplar a geração de energia no país. Nessa reflexão, algumas considerações foram levantadas para detalhar as narrativas dos enunciados, retomando a reflexão de Irwin (2008), que assume que a ciência é definidora dos desafios ambientais modernos. Portanto, detalharemos aqui algumas pistas geradas a partir da controvérsia formada no estudo de caso, no desafio de explicitar como é acionada a ciência para explicitar os desafios ambientais que estão associados às alterações provenientes da construção da Usina.

A primeira pista que ajuda a pensar como Belo Monte se torna sustentável surge quando a rede do programa de ação aciona a neutralidade científica em relação às escolhas políticas na construção dos fatos. Esta relação é encerrada em uma caixa-preta que faz sumir as associações e seus arranjos. Essas só são acessadas quando a rede do antiprograma abre a controvérsia e questiona a construção dos fatos. $\mathrm{O}$ enunciado vencedor engaja em sua rede cientistas conceituados, recursos financeiros e materiais para realizar um longo mapeamento (tanto temporal quanto espacial) na construção de um estudo de grande amplitude capaz de elaborar um conhecimento geral sobre o rio Xingu. Contudo, ao selecionar as metodologias macro, em detrimento dos impactos localizados, revela o engajamento político de seus resultados. Estes, compõem os relatórios técnicos que fazem a mediação entre a atuação dos pesquisadores consultores e os critérios estabelecidos pelo IBAMA, subdimensionando os impactos locais. Os actantes políticos são os mediadores que impulsionam a versão da rede do programa de ação sobre a realidade local, construída artificialmente e sem o apoio dos pescadores que não legitimaram o estudo feito pela rede do programa.

A pesquisa engajada também faz parte dos estudos independentes, visto que os pesquisadores são comprometidos em mostrar as alterações ambientais na região. Contudo, problematizam que não há neutralidade científica e que as escolhas políticas são feitas no engajamento dos pescadores e nas escolhas metodológicas da pesquisa. $\mathrm{O}$ engajamento ocorre na mobilização das pessoas que estão na linha de frente da controvérsia para participar da construção desses estudos. Contudo, a rede perde fôlego no envolvimento de actantes capazes de acionar redes mais amplas dentro das esferas estatais.

A segunda pista para o encerramento da controvérsia diz respeito ao poder de mobilização e engajamento de actantes que a rede do programa de ação é capaz de aglutinar. Como argumenta Mitchell (2013), o Estado, juntamente com o empreendedor, impõe pressões econômicas e políticas que são capazes de limitar as possibilidades técnicas e científicas. A capacidade de associar actantes hegemônicos, mesmo que sua versão sobre o fato seja altamente contraditória e frágil, é a forma que o Estado tem para mostrar seu poder tecnoeconômico (Mitchell, 2013) e impor novas dinâmicas ao ambiente. Como visto nesta controvérsia, ele detém o poder de mobilizar actantes que se destacam no 
direcionamento dos encaminhamentos relativos ao curso do rio e da vida dos pescadores na região, impondo a reorganização dos meios natural e social com a construção da Usina "sustentável".

Entretanto, essa construção é artificial, e a realidade enfrentada localmente obrigou os pescadores a se adaptar percorrer longas distâncias para pescar a mesma quantidade de peixes que pescavam próximo de suas casas. Os indígenas começaram a sentir a pressão em suas áreas de pesca pela presença de pescadores citadinos e os conflitos ambientais em torno da manutenção de suas formas de interação com a natureza e de suas vidas foram sentidos com mais intensidade. As traduções de sociedade e natureza operadas pela rede do antiprograma de ação não desaparecem com a construção de Belo Monte, nem ao reforçar a obra como "sustentável". Ao contrário, a rede segue lá, compondo vidas e possibilidades de negociação com o ambiente alterado. Isso significa que a sociedade e a natureza moldados na construção de Belo Monte não são construções estanques, mas que terão de ser constantemente negociados.

A terceira pista gerada pelo encerramento da controvérsia reside na sustentação de uma objetividade sem consenso, baseada no debate sobre o contraditório exposto pelos dados técnicos e científicos relativos aos efeitos adversos da Usina. Se o consenso sobre a objetividade e a construção de fatos é a atividade que move a ciência, pode-se afirmar que a rede do programa constrói factóides (Marras, 2020) porque não aparam suas decisões em discussões científicas, mas sim na delimitação política da versão que mais convém. Ao blindar seus estudos da controvérsia não participam da produção de consenso quanto à objetividade dos fatos (Marras, 2020) que defendem. Essa afirmação é feita porque a rede do programa de ação não assimila a crítica mobilizada pela rede doantiprograma de ação, e, portanto, não altera suas conclusões sobre a pesca na região.

Em face aos efeitos inegáveis no rio, nos pescadores e na Volta Grande, manifestações nos canteiros geraram um acordo pouco efetivo às demandas dos pescadores. Assim, a rede do programa de ação aciona a ciência e a tecnologia para construir um enunciado vencedor que produz uma sustentabilidade seletiva e hegemônica. Pescadores e indígenas da região, agentes que fazem uso do rio Xingu para sua sobrevivência, são envolvidos no que De la Cadena chamou de "anthropo-not-seen" (De la Cadena, 2016, p. 255), ou seja, são grupos sociais que não são vistos durante a viabilidade ambiental da Usina, mas que se colocam resistentes ao processo. A miopia operada pela rede do programa ocorre porque as categorias tradicionais, que apartam humanos e não humanos, são tensionadas pela experiência dos pescadores que, por sua vez, também operam amparando os estudos acadêmicos do antiprograma, comprometidos com aquela realidade e sensíveis ao diálogo com a população ribeirinha e indígena.

A distopia destinada por Belo Monte aos pescadores é o objeto de crítica da rede do antiprograma de ação, mesmo que ainda encontre espaço limitado para atuar. Nunes e Matias (2003) apontam que essa rede constitui uma forma de articulação política que leva ao público as controvérsias e busca dar respostas "a situações saturadas de incerteza, respostas que passam, necessariamente, por novas articulações entre o conhecimento e a ação política" (Nunes e Matias, 2003, p. 149). Através dessas pistas sugere-se fortalecer a relação entre o Estado democrático, os espaços públicos operantes, a ciência e a tecnologia, visando ampliar o escopo 
de negociação da rede do antiprograma de ação no licenciamento ambiental, fortalecendo os espaços democráticos nessas esferas para assistir as sustentabilidades associadas aos diferentes modos de viver com o rio Xingu.

A rede do programa de ação realiza uma construção arbitrária que sonega aos pescadores da região soluções funcionais às suas demandas, excluindo da vida destes os efeitos sustentáveis prometidos pela construção da obra. É preciso questionar o quanto é possível mitigar os efeitos da obra se os estudos são insuficientes, parciais, baseados em amostragens e localizações não representativas do conjunto dos impactos. Nesse contexto, entende-se que explorar controvérsias é como atuar nas frestas (Marras, 2020) para expor como a ciência opera para construir fatos e constranger versões hegemônicas.

O estudo da controvérsia sobre a pesca trouxe elementos significativos para pensar os critérios de demarcação dessas conceituações no processo de licenciamento ambiental. Cabe ainda realçar a atualidade dessa temática, que extrapola lições geradas pela experiência de Belo Monte, uma vez que megaprojetos, como, por exemplo, o Complexo Tapajós, avançam a passos largos sobre os rios amazônicos $\mathrm{e}$, resguardadas as singularidades, apontam para a mesma escala de efeitos sociais, naturais e institucionais já mapeados. É também um tema de interesse sociológico que exige um processo contínuo de reflexão sobre as possibilidades de flexibilizar tanto as categorias hegemônicas produzidas pela Política e pela Ciência quanto repensar categorias arraigadas na tradição sociológica.

\section{Referências}

ANEEL - Agência Nacional de Energia Elétrica (Brasil). Atlas de energia elétrica do Brasil. 3. ed.- Brasília: ANEEL, 2008.

BRASIL. Decreto Legislativo n ${ }^{\circ} 788$, de 2005. Autoriza o Poder Executivo a implantar o Aproveitamento Hidroelétrico Belo Monte, localizado em trecho do rio Xingu, no Estado do Pará, a ser desenvolvido após estudos de viabilidade pela Centrais Elétricas Brasileiras S.A. - Eletrobrás. Senado Federal.

Beck, U. Sociedade de risco: rumo a uma outra modernidade. São Paulo: Editora 34, 2010.

Beck, U. Interview/Ulrich Beck: system of organized irresponsibility behind the Fukushima crisis by Bears Chat at The Wall Street Examiner, 2011. Disponível em: <https:// wallstreetexaminer.com/2011/07/interview-ulrich-beck-system-of-organized-irresponsibility-behind-the-fukushima-crisis/>. Acesso em: ago. 2021.

Bibeau, G. Desenvolvimento sustentável "made in Quebec". Políticas de proteção ao meio ambiente e biotecnologias. Sociologias, 13 (26), 202-226, 2011. doi: 10.1590/S151745222011000100009

Blanco-Wells, G. La vida social de la energía: apuntes para el estúdio territorializado de las transiciones energéticas. Sociologias, 21(51), 160-185, 2019. doi: 10.1590/151745220215106

CIMI - Conselho Indigenista Missionário. Os povos indigenas do Xingu e a hidrelétrica Belo Monte, 2008. Disponível em: <https://cimi.org.br/2008/06/27578/>. Acesso em: jan. 2021.

Comissão Mundial Sobre Meio Ambiente e Desenvolvimento. Nosso futuro comum. Rio de Janeiro: Editora: Fundação Getúlio Vargas, 1991.

Costanzo, A; Sànchez, L. Gestão do conhecimento em empresas de consultoria ambiental. São Paulo: Poli/Usp, 2013.

De La Cadena, M. Naturaleza disociadora. Boletín de Antropología. Universidad de Antioquia, Medellín, 31(52), 2016. Disponível em: $<$ https://revistas.udea.edu.co/index. 
php/boletin/article/view/326878>. Acesso em: fev. 2021.

ELETROBRÁS - Centrais Elétricas Brasileiras S.A. Aproveitamento Hidrelétrico Belo Monte: Estudo de Impacto Ambiental. Rio de Janeiro: Eletrobrás, 36 vols, 2009.

EPE - Empresa de Pesquisa Energética. (Org) Tolmasquim, M. T. Energia Termelétrica: Gás Natural, Biomassa, Carvão, Nuclear. Rio de Janeiro, 2016. Disponível em: <https:// www.epe.gov.br/sites-pt/publicacoes-dados-abertos/publicacoes/PublicacoesArquivos/publicacao-173/Energia\%20 Termel\%C3\%A9trica\%20-\%20Online\%2013maio2016. pdf $>$. Acesso em: dez. 2020.

EPE - Empresa de Pesquisa Energética. Balanço Energético Nacional 2018: Ano base 2017. Rio de Janeiro, 2018. Disponível em: <https://www.epe.gov.br/sites-pt/publicacoes-dados-abertos/publicacoes/PublicacoesArquivos/ publicacao-303/topico-419/BEN2018_ Int.pdf $>$. Acesso em: dez. 2020.

Faria, I. D. O descompasso e o piroscópio: uma análise dos conflitos socioambientais do projeto da Usina Hidrelétrica Belo Monte. Brasília, Tese (Doutorado em Desenvolvimento Sustentável) - UnB, 2004.

Falcão, A. Belo Monte: uma usina de conhecimento. Rio de Janeiro: Insight, 2010.

FGV - Fundação Getúlio Vargas. Plano de Desenvolvimento Regional Sustentável do Xingu. 2016. Disponível em: $<$ http://mediadrawer.gvces.com.br/publicacoes/original/indicadores-de-belo-monte-2016.pdf > . Acesso em fev. 2021.

Fleury, L.; Almeida, J. A construção da Usina Hidrelétrica de Belo Monte: conflito ambiental e o dilema do desenvolvimento. Ambiente \& Sociedade, 16(4), 141-156, 2013. doi: 10.1590/S1414-753X2013000400009

Fleury, L.; Almeida, J.; Premebida, A. O ambiente como questão sociológica: conflitos ambientais em perspectiva. Sociologias, 16 (35), 34-82, 2014. doi: 10.1590/S151745222014000100003

Francesco, A; Carneiro, C. (Orgs.). Atlas dos impactos da UHE Belo Monte sobre a pesca. São Paulo: Instituto Socioambiental, 2015. Disponível em: <https://ox.socioambiental.org/sites/default/files/ficha-tecnica/node/202/ edit/2018-06/atlas-pesca-bm.pdf $>$. Acesso em: jan. 2021.
Irwin, A. A ciência e a construção dos problemas ambientais. In: Nunes, J. A.; Roque, R. (Orgs.). Objectos impuros: experiências em estudos sobre a ciência. Lisboa: Edições Afrontamento, p. 95-105, 2008.

Kinsella, W. J. Being "Post-Fukushima": divergent understandings of sociotechnical risk. Fukushima Global Communication Programme, Working Paper Series, 18, 2015. Disponível em: $<$ https://i.unu.edu/media/ias.unu. edu-en/news/12850/FGC-WP-18-FINAL.pdf > . Acesso em: fev. 2021.

Latour, B. Jamais fomos modernos. São Paulo: Editora 34, 1994.

Latour, B. Ciência em ação: como seguir cientistas e engenheiros sociedade afora. São Paulo: Editora Unesp, 2000.

Latour, B. Cogitamus: seis cartas sobre as humanidades científicas. São Paulo: Editora 34, 2016.

Latour, B. Qual cosmos, quais cosmopolíticas? Comentário sobre as propostas de paz de Ulrich Beck. Revista do Instituto de Estudos Brasileiros, 69, 427-441, 2018. doi: 10.11606/issn.2316-901X.v0i69p427-441

Leme. Estudo de Impacto Ambiental do Aproveitamento $\mathrm{Hi}$ drelétrico Belo Monte, v. 6, 2009. Disponível em: <https:// servicos.ibama.gov.br/licenciamento/consulta_empreendimentos.php>. Acesso em: ago. 2021.

Leroy, J.; Acselrad, H. Apresentação. In: Leroy, J.; Acselrad, H.; Melo, C.; Malerba, J. (Orgs.). Projeto de avaliação de equidade ambiental como instrumento de democratização dos procedimentos de avaliação de impacto de projetos de desenvolvimento. Rio de Janeiro: Fase; Ettern, 2011.

Magalhães, S.; Hernandez, F. del M. (Orgs.). Painel de especialistas: análise crítica do Estudo de Impacto Ambiental do Aproveitamento Hidrelétrico de Belo Monte. Belém, 29 de outubro de 2009. Disponível em: $<$ https://xinguvivo.org. br/wp-content/uploads/2010/10/Belo_Monte_Painel_especialistas_EIA.pdf>. Acesso em: dez. 2020.

Marras, S. O vozerio da pós-verdade e suas ameaças civilizacionais. In: Oliveira, J; Amoroso, M.; Lima, A.; Shitatori, K.; Marras, S.; Emperaire, L. (Orgs.). Vozes vegetais: diversidade, resistências e histórias da floresta. São Paulo: Ubu Editora, 2020. 
Mitchell, T. ¿Puedehablarel mosquito? In: Rodriguez, M. C. (Org.). Cosmopolíticas: perspectivas antropológicas. Madrid: Editorial Trotta, p. 299-340, 2013.

Müller-Plantenberg, C.; Ab'Saber, A. Previsão de impactos. São Paulo: Edusp, 1998.

NESA - Norte Energia Sociedade Anônima. Acordo de Cooperação Técnica (ACT) nº 006/2014, 2014.

Nunes, J. A.; Matias, M. Controvérsia científica e conflitos ambientais em Portugal: o caso da co-incineração de resíduos industriais perigosos. Revista Crítica de Ciências Sociais, 65, 129-150, 2003. doi: 10.4000/rccs. 1185

PAC - Programa de Aceleração do Crescimento. $6^{\circ}$ Balanço: 2015- 2018, 2018. Disponível em: <http://pac.gov.br/pub/ up/relatorio/11fbe9b2f7cbecb3ec5c1f9f67b5f3be.pdf $>$. Acesso em: fev. 2021.

Prates, C.; Peixoto, L. Hidrelétrica Belo Monte: da controvérsia sobre energia limpa à produção da "verdade científica”. Revista Ciências Sociais Unisinos, 56, 80-93, 2020. doi: 10.4013/csu.2020.56.1.08

Porto, M. F. de S.; Finamore, R.; Ferreira, H. Injustiças da sustentabilidade: conflitos ambientais relacionados à produção de energia "limpa" no Brasil. Revista Crítica de Ciências Sociais, 100, 37-94, 2013. doi: 10.4000/rccs.5217
Queiroz e Melo, M. de F. A. de. Mas de onde vem o Latour? Pesquisas e Práticas Psicossociais, 3(1), 2-12, 2008.

Rodrigues, L. R. Ciência no tribunal: as expertises mobilizadas no caso Belo Monte. Santa Maria, Dissertação (Mestrado em Ciências Sociais) - UFSM, 2013.

Sevá Filho, O. (Org.). Tenotã-Mõ. Alertas sobre as consequências dos projetos hidrelétricos no rio Xingu. Internacional Rivers Network, 2005. Disponível em: <http://www.fem. unicamp.br/ seva/Tenota-Mo_caps1a3_pag92.pdf $>$. Acesso em: maio 2021.

Sklair, L. The corporate capture of sustainable development and its transformation into a 'good Anthropocene' historical bloc. Civitas, 19(2), 296-314, 2019. doi: 10.15448/19847289.2019.2.31970

Stengers, I.; Pignarre, P. La sorcellerie capitaliste: pratiques de désenvoûtement. Paris: La Découverte, 2005.

Tancredi, M.; Abbud, O. Por que o Brasil está trocando as hidrelétricas e seus reservatórios por energia mais cara e poluente? Consultoria Legislativa, 2013. Disponível em: $<$ https://www2.senado.leg.br/bdsf/item/id/496199>. Acesso em: dez. 2020.

Zhouri, A.; Laschefski, K. Desenvolvimento e conflitos ambientais um novo campo de investigação. In: Zhouri, A.; Laschefski, K. (Orgs.). Desenvolvimento e conflitos Ambientais. Belo Horizonte, Editora UFMG, p. 11-34, 2010. 